\title{
FUNCTION INTEGRATED TRACK SYSTEM
}

\author{
Eberhard Hohnecker $^{1}$
}

The paper discusses a function integrated track system that focuses on the reduction of acoustic emissions from railway lines. It is shown that the combination of an embedded rail system (ERS), a sound absorbing track surface, and an integrated mini sound barrier has significant acoustic advantages compared to a standard ballast superstructure. The acoustic advantages of an embedded rail system are particularly pronounced in the case of railway bridges. Finally, it is shown that an ERS with track integrated vibration sensors may be used as an early warning system and for monitoring the structural health of the railway infrastructure.

Key words: embedded rail system, mini sound barrier, track integrated sensors, structural health monitoring

\section{Introduction}

The paper reviews recent developments and designing the FiL-Rail system as a function integrated track system.

A novel type of railway slab-track system consisting of the 4 elements

- $\quad$ FiL-Rail ERS: $\quad$ continuously-elastically supported and embedded rail system

- $\quad$ FiL-Rail MSW: low-height sound barrier

- $\quad$ ERS-EcoTrack: sound absorbing plant-based track surface

- LN-Bridge: low noise bridge system

is described in some detail below.

${ }^{1}$ prof. Dr. Ing. E. Hohnecker, Department of Railway Systems, Institute of Road and Railway Systems, University of Karlsruhe (TH), Otto-Ammann-Platz 9, 72131 Karlsruhe, Germany, Tel.: +49-721-608-2248, Email: eisenbahn@ise.uka.de 

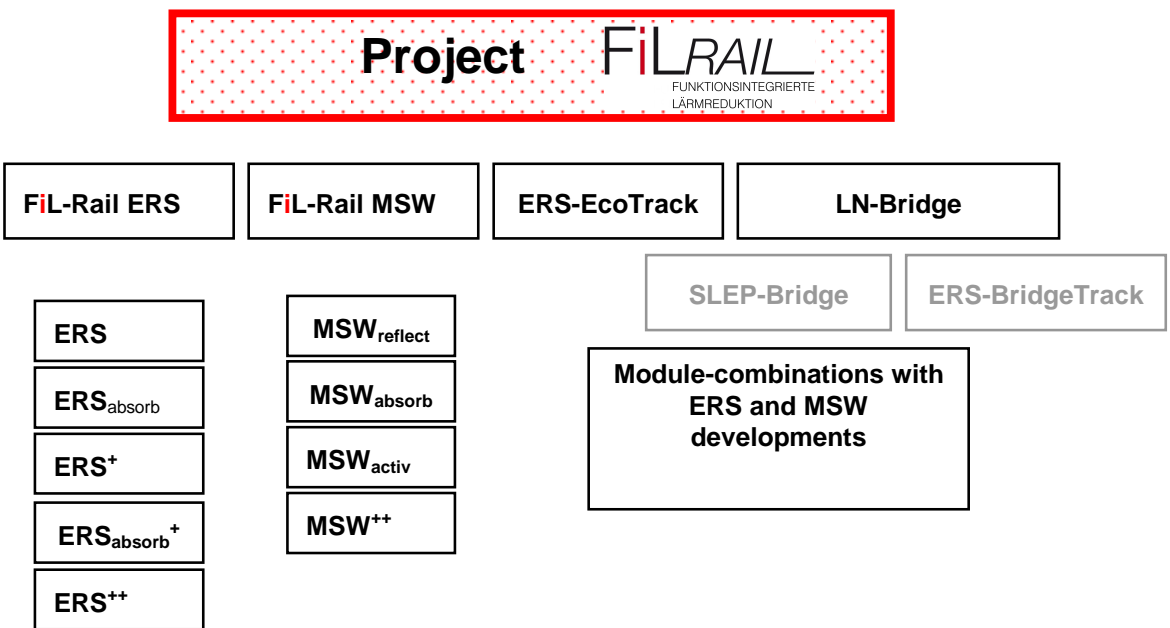

Fig. 1: $\quad$ FiL-Rail structure - elements and modules

Figure 1 shows the structure of the FiL-Rail project. The basic elements (first row) and their modules (columns) are shown. The element LN-Bridge consists of the two subelements Slep-Bridge and ERSBridgeTrack. Combination of these elements in the FiL-Rail system has several acoustic, ride comfort, and wearing advantages compared to standard ballast or slab track systems.

Another line of research concerns the integration of specific sensors into the railway superstructure. Such devices could serve a multitude of additional functions. For example, vibration sensors are useful for permanent and continuous infrastructure monitoring, flat spot detection as well as avalanches and rock fall detection, earthquake and unauthorised access early warning (see sect.6)

\section{Element FiL-Rail ERS}

The main function of the railway superstructure is to supply guiding and load support for the rail vehicles. The rails serve as guiding and load support devices. Further load transfer is achieved by a system of elastic layers with decreasing stiffness from top to bottom. This guarantees that the wheel load of typically $100 \mathrm{kN}$ is distributed over increasingly larger areas thereby reducing the stresses in each consecutive layer.

In traditional ballast or slab track railway superstructures the rails are discretely fastened onto cross sleepers that are periodically placed along the track. The fastening devices are usually elaborate systems consisting of numerous components at each support point, such as bolts, nuts, clamps. The sleepers support and distribute the axle load of the vehicle to the ballast. In addition, they provide sufficient lateral track stiffness so that a constant track gauge is maintained.

On the other hand, a continuous rail fastening system such as the FiL-Rail ERS does not employ any of the usual rail fastening components. Instead the rails are placed in a concrete trough and fixed by a pourable elastomer material (polyurethane with cork granulate), called corkelast. The corkelast surrounds the rail foot, rail web, and part of the rail head. The elastic pad is responsible deflection (see Fig. 2). Special adhesives guarantee that rail, corkelast, and concrete form a tight and permanent connection. 


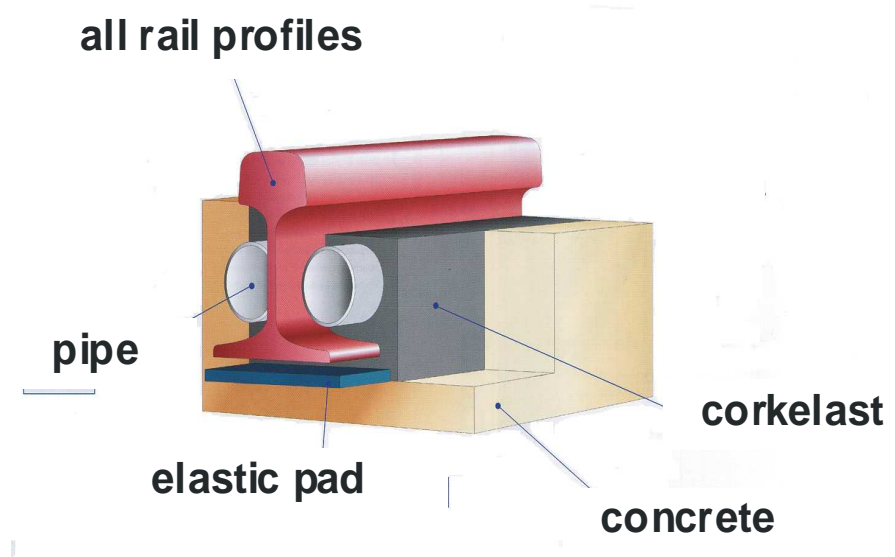

Fig. 2: Components of the slab track system FiL-Rail ERS

The complete embedding of the rails in the corkelast material provides continuous elastic rail support, both in vertical and horizontal directions. Thus the rails are fixed and elastically supported over their entire length and not only at discrete points as in standard railway superstructures. This has a number of consequences for the acoustic behaviour of the system both with respect to the ground-borne vibration and airborne sound emissions.

\subsection{Ground-borne vibration}

Ground-borne vibration measurements at several ERS test sites have shown considerably lower vibration levels than a standard ballast superstructure [3,5,6]. As an example, we display in Fig. 3 the results of vibration velocity measurements made at an ERS and a ballast reference track in Stuttgart, Germany [3]. The data were taken with geophones positioned at about $0.9 \mathrm{~m}$ from the track recording the vibrations in vertical and horizontal directions. Comparing the solid (ERS) and dashed (ballast) track, we observe that the ERS has considerably lower horizontal vibration levels, e.g., at $80 \mathrm{~Hz}$, the difference in vibration levels is $\Delta \mathrm{L}(80 \mathrm{~Hz})=20 \log (0.71 / 0.066)=21 \mathrm{~dB}_{\mathrm{v}}$.

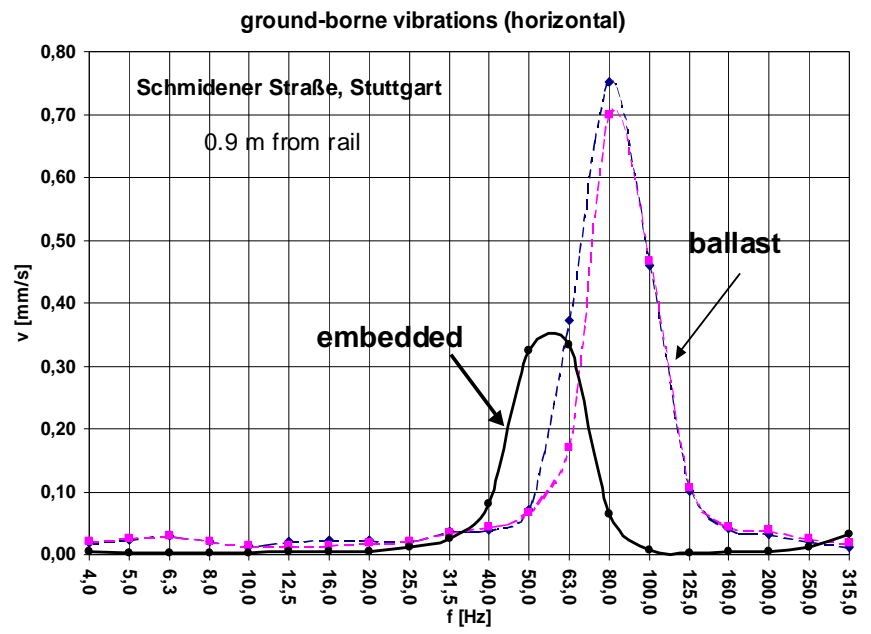

Fig. 3: Horizontal (orthogonal to the track) vibration velocity $\mathrm{v}[\mathrm{mm} / \mathrm{s}]$ as function of frequency'f [Hz] measured at $0.9 \mathrm{~m}$ from the outer rail. ERS (solid line) ballast track (dashed-line) 
There are several reasons for the reduced vibration emissions of an ERS. In contrast to standard ballast track systems or slab track systems with discrete rail support, an ERS with continuously supported rails does not lead to vibrations with the discrete support frequency $f=v / a$, where $v$ is the train velocity and $a$ the distance between the discrete support points (e.g. sleeper distance). Another reason is that the continuous elastic support of the tracks allows to work with rather soft rail-pads. This shifts the first superstructure resonance frequency to lower frequencies and thus reduces vibrations above this resonance frequency. Furthermore, the corkelast material provides rather effective vibration damping especially in resonance regions.

\subsection{Airborne sound emission}

Different railway superstructures have different characteristic emission spectra as clearly visible by the different positions of the airborne sound emission maxima in Fig.4. The spectrum of the ERS has a maximum at around $600 \mathrm{~Hz}$ where its levels exceed those of the ballast track by about $10 \mathrm{~dB}$. On the other hand, at higher frequencies above $2000 \mathrm{~Hz}$, where the human ear has its highest sensitivity, the ERS levels are lower than the ballast track by about $7 \mathrm{~dB}$ [4]. This reduction at higher frequencies leads to the subjective impression that train passages over an ERS track sound less annoying.

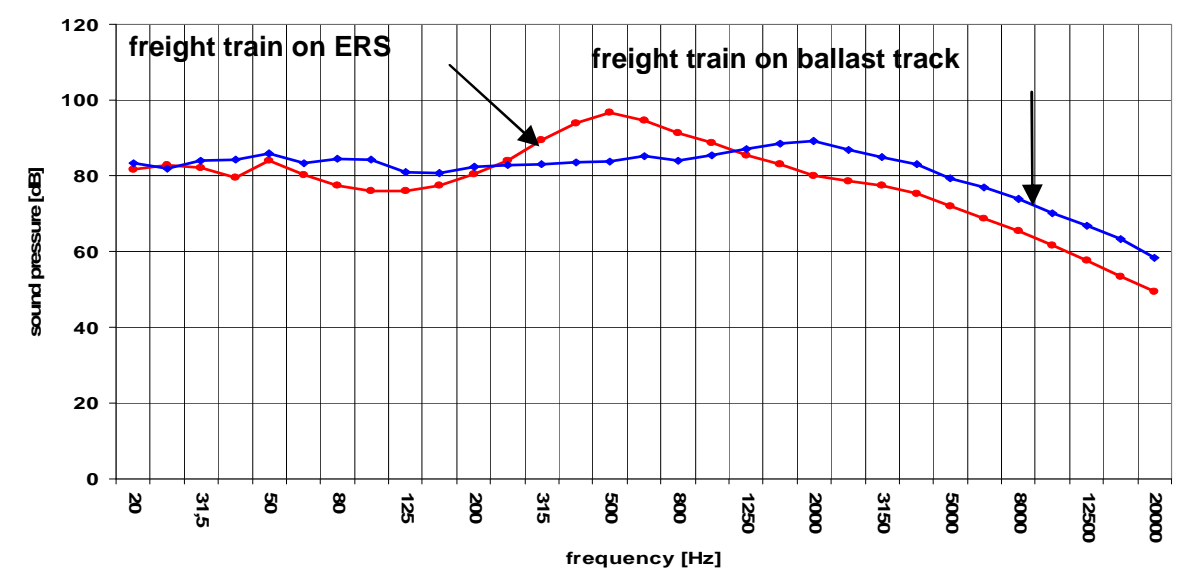

Fig. 4: Comparison of airborne sound pressure levels $[\mathrm{dB}]$ as a function of frequency [Hz] from ERS and adjacent ballast track measured at a distance of $5.3 \mathrm{~m}$ from the ERS track at the Deutsche Bahn test site in Waghäusel [2]

On the other hand, when summed over all frequency bands, the total airborne sound emission level from an ERS is about $5 \mathrm{~dB}$ higher than the corresponding ballast track level. The reason for the overall higher sound emission of the embedded rail slab track compared to the ballast track is partly due to the very low sound absorption coefficient of the concrete slab surface and partly due to constructive differences (e.g. continuous vs. discrete rail support). Therefore, further improvements of the acoustic properties of the ERS are necessary.

\section{Element FiL-Rail MSW}

Considerable reductions of airborne noise emissions can be achieved by combining an ERS with low height sound barriers (MSW). Low height sound barriers close to the track (Fig. 5) are an effective way to reduce the sound emission in railway traffic. Their effectiveness depends mainly on the position with 
respect to the track, geometry, material, and surface structure. An acoustic optimization should also take into account the properties of the railway superstructure.

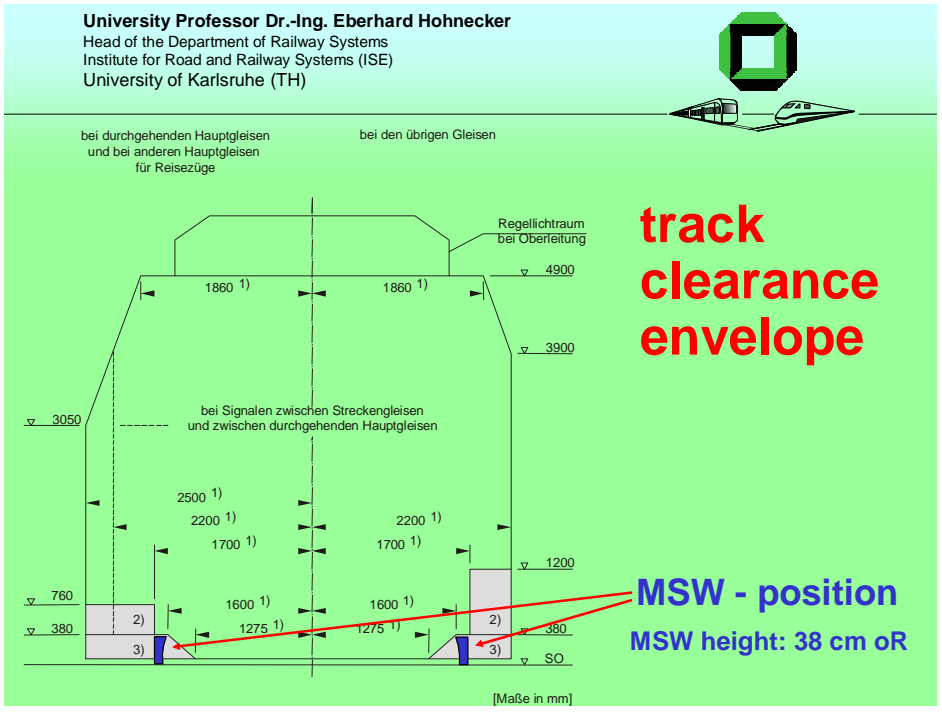

Fig. 5: MSW position in the heavy rail track clearance envelope

Up to about $250 \mathrm{~km} / \mathrm{h}$ the rolling noise generated by the wheel-rail interaction is the major emission source. The highest noise reductions are obtained if the MSW is installed as close as possible to the sound source (track).

Fig. 6 shows multiple reflections of a sound ray from the track surface and the MSW. In each successive reflection from these sound absorbing surfaces the intensity of the sound ray is reduced. To achieve high reductions it is important to adjust the acoustic properties of the MSW and the track surface to the frequency spectrum of the noise source. For example, in combination with the FiL-Rail ERS, the track and MSW surfaces should have a high absorption coefficient in the frequency range around $630 \mathrm{~Hz}$. Table 1 gives a summary of the results.

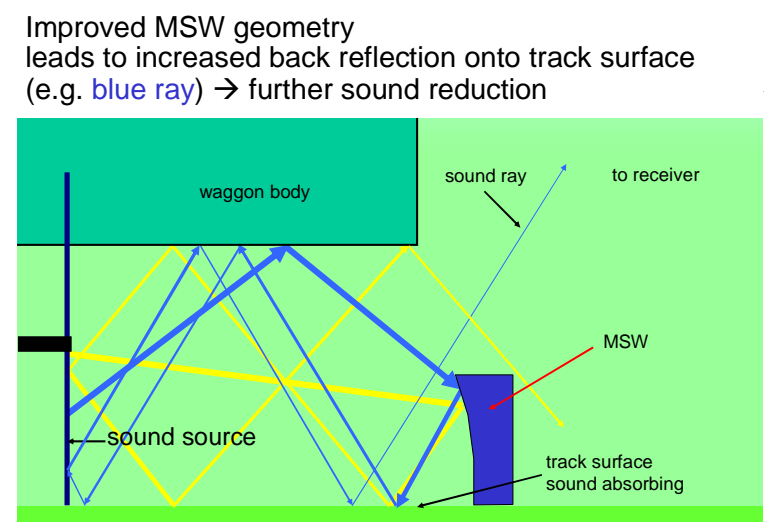

Fig. 6: The path of typical sound rays emitted from the wheel-rail source is shown. Multiple reflections from the sound absorbing track and MSW surfaces lead to a reduction of the sound levels at the receiver. 
Table 1: Calculated sound pressure level $[\mathrm{dB}]$ at $630 \mathrm{~Hz}$ at a height of $3.5 \mathrm{~m}$ above the track and a distance of $10 \mathrm{~m}$ from the track for a rectangular MSW geometry

\begin{tabular}{|l|l|l|}
\hline surface material & concrete & grass \\
\hline without MSW & $97 \mathrm{~dB}$ & $92 \mathrm{~dB}$ \\
\hline with MSW & $92 \mathrm{~dB}$ & $85 \mathrm{~dB}$ \\
\hline
\end{tabular}

In addition to its function as a noise barrier, the MSW may also increase the safety of inner-city railway lines. The crossing of railway lines by cars and pedestrians is a major safety problem. In the case of a ballast superstructure, the track is usually recognized and respected as a separate tramway. On the other hand, in the case of a slab track, unauthorized crossings by pedestrians are frequently observed. An MSW is a clearly visible obstacle that prevents, for example, crossings with baby carriages and bicycles which have a major accident risk.

\section{Element FiL-Rail ERS-EcoTrack ${ }^{1}$}

In the case of rail bound urban transportation systems, it is sometimes desirable to combine an ERS with a plant-based track surface (see Fig. 2). This does not only reduce the airborne sound emissions from the track but has also other environmental advantages. For example, a plant based track surface can bind small dust particles and other air pollutants, and thus act as an urban air filter. In addition, certain plants are able to retain and slowly evaporate the rainwater thereby reducing the amount of waste water entering the sewage system at a given time. These and other ecological effects of a plant based track surface like FiL-Rail ERS-EcoTrack may considerably improve the urban micro climate.

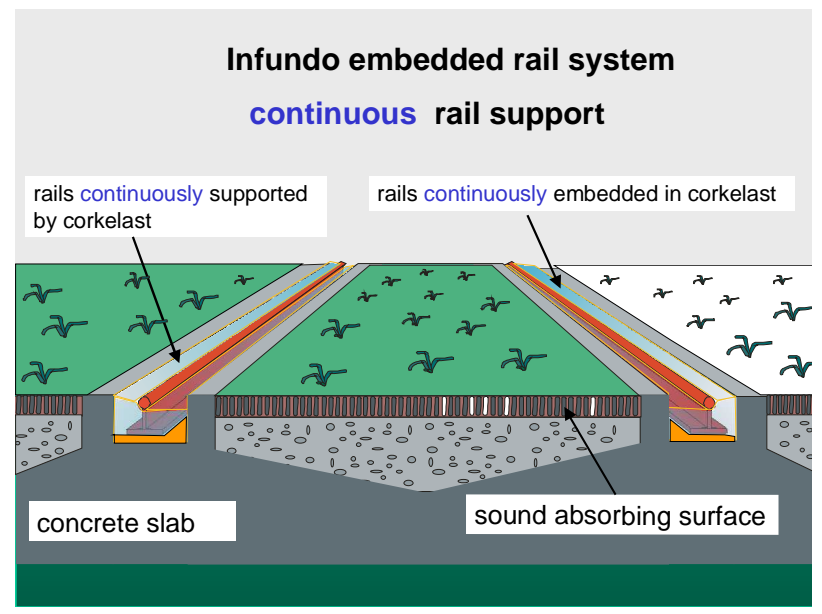

Fig. 7: ERS EcoTrack

\section{Element FiL-Rail LN-Bridge}

When a train passes over a bridge there is in addition to the usual rolling noise also the sound emitted from the vibrating bridge structure. The latter is the main noise source. In the case of steel bridges the sound emission is typically $20 \mathrm{~dB}$ higher compared to a regular track section.

${ }^{I}$ plant-based track surface 


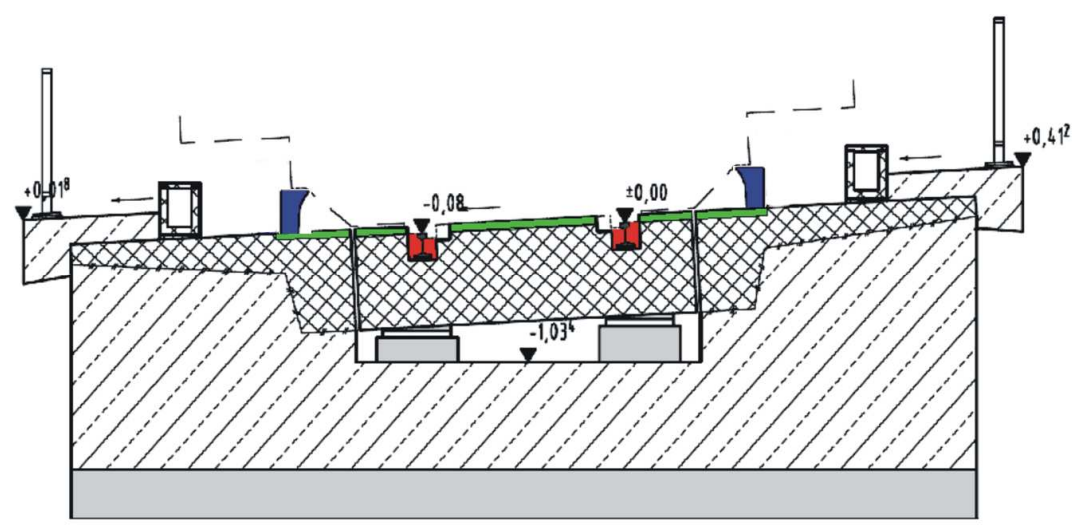

Fig.8: LN-Bridge - type SLEP-Bridge - ERS bridge with low height sound barrier MSW

The frequency spectra emitted from a regular track and from railway bridges are very different. It is well known that the rolling noise has its highest levels in the frequency range between $500-2000 \mathrm{~Hz}$ (see section 2.1), whereas the sound emissions from railway bridges peak typically in the range between 50$125 \mathrm{~Hz}$.

The reason for the increased sound emission from bridges in this low frequency range is the following. A train passage over a discretely supported track superstructure leads to excitations with a discrete support frequency $\mathrm{f}=\mathrm{v} / \mathrm{a}$, where $\mathrm{v}[\mathrm{m} / \mathrm{s}]$ is the train velocity and $\mathrm{a}[\mathrm{m}]$ is the distance between consecutive support points, i.e. the sleeper distance. For train velocities of $v=120(260) \mathrm{km} / \mathrm{h}$ and a sleeper distance of $\mathrm{a}=60 \mathrm{~cm}$ one obtains $\mathrm{f}=55(120) \mathrm{Hz}$. However, in this range is not only the first resonance frequency of the railway superstructure but also the eigenfrequencies of various bridge components. The close correspondence of the discrete support excitation frequency with the eigenfrequencies of railway superstructures on one hand, and typical bridge components on the other hand, leads to increased vibrations of these bridge components (e.g. box girder). This explains the increased sound emission from railway bridges with discretely supported rails.

However, if a track system with continuous elastic rail support is employed there is no excitation with the discrete support frequency. As a result one expects that the sound emission from an ERS bridge will be substantially lower compared to a standard bridge.

\section{Continuous infrastructure monitoring}

An interesting aspect of rail bound systems is the possibility to integrate into the existing rail network additional sensors and corresponding electrical wiring needed for transmitting the sensor data to train control centres.

For example, stationary vibration sensors (e.g. accelerometers) in the track can be used to monitor the structural integrity of various railway infrastructure components, such as the rails themselves or bridges. In particular, the detection and continuous monitoring of significant deviations in track geometry and rail/wheel profiles (e.g. flat spot detection) could prove useful for the infrastructure owners as well as for railway operators.

Moreover, a dense network of track integrated accelerometers could also serve as an earthquake early warning system. The high density provided by such a sensor network could increase the warning times and improve the accuracy of the earthquake damage predictions. In order to avoid false alarms, it is mandatory that the seismic P-wave signals recorded by these accelerometers be clearly distinguishable 
from train passage induced vibrations. This requirement can be satisfied because the characteristic frequency spectra of seismic events and of train passages are rather different. In addition, such a sensor network could prove useful for the early detection of avalanches, rockfalls, as well as unauthorized track access.

Currently, the train control and protection infrastructure of different European countries is redesigned with the aim of achieving technical interoperability between different EU member states [1]. Therefore, it is timely to ask the question: How must the train control infrastructure be modified so that it can be used for continuous track state monitoring as well as for earthquake early warning purposes?

To answer this question, we are currently investigating within a research project called "Early warning system Transport" the feasibility of integrating suitable sensors into the track [7]. In a second phase, it is planned to design and build a test track section in order to test the infrastructure monitoring and early warning system in practice. For this purpose a continuously-elastically supported ERS track is particularly suited because it uses only few structural components compared to a standard ballast track.

\section{Summary}

In summary, one may say that an embedded rail system with sound absorbing plant-based track surface and an integrated LSB has definite acoustic advantages compared to a standard ballast and most slab track systems, both with respect to ground-borne vibration and airborne noise emission protection.

The acoustic advantages of an ERS are particularly pronounced in the case of railway bridges. The continuous elastic rail support of an ERS does not lead to discrete support frequency excitations, which are the main cause of noise emissions from standard bridges.

Finally, a railway network with integrated sensors may be useful for earthquake early warning and permanent infrastructure monitoring purposes. The different track components discussed here are not merely a collection of disjointed parts but all parts should be viewed as intricately connected both in structure and function.

\section{Reference literature}

1. Berger, R. et al., The way to a coordinated deployment of ERTMS/ETCS throughout the European network, Railway Technical Review, 4 (2005) pg.21.

2. Buchmann, A., "Luftschallmessungen an der DB-Teststrecke in Waghäusel", Internal report, University of Karlsruhe (2003).

3. Elbert, M., "Experimentelle Überprüfung eines Körperschallprognose-modells", Diploma thesis, University of Karlsruhe (2002)

4. Hohnecker, E., "Acoustic properties of railway superstructures", World Congress on Railway Research, 28 Sept.-1 Oct. 2003, Edinburgh.

5. Müller-BBM, "Oberbausystem Infundo, Körperschalltechnische Untersuch-ungen im Bereich der Straßenbahn München”, Bericht Nr. 34389/5, Nov. 1997

6. Röthlingshöfer, F., "Erschütterungstechnische Analyse eines Straßenbahnober-baus, Fallstudie Therese gate, Oslo", Diploma thesis, University of Karlsruhe (2002).

7. Wenzel, F. et al., Early warning system for transport lines, Geotechnologien, Science Report No.10 (2007) 